\title{
Coupling of MBP fusion protein cleavage with sparse matrix crystallization screens to overcome problematic protein solubility
}

\author{
Franz Gruswitz, Mary Frishman, Barry M. Goldstein, and Joseph E. Wedekind \\ University of Rochester School of Medicine and Dentistry, Rochester, NY, USA
}

BioTechniques 39:476-480 (October 2005)

doi 10.2144/000112033

Nuclear magnetic resonance (NMR) and crystallographic techniques require large quantities of pure, soluble protein. However, numerous target proteins exhibit limited solubility resulting in low recovery and reduced concentrations following purification. Molecular biological techniques have been developed to assist in this area including the use of a fusion protein attached to the $\mathrm{N}$ or $\mathrm{C}$ terminus. For example, maltose binding protein (MBP) can increase solubility (1), although its proteolytic removal often results in precipitation of the target protein. Furthermore, efforts to prepare diffraction quality crystals of MBP fusion proteins have required laborious optimization of linkers, ultimately yielding crystals of limited diffraction quality (2). Mutations of surface residues can improve solubility, but this often requires knowledge of the protein structure. More comprehensive approaches, such as sparse matrix screening (3), have yielded greater success. Examples include cell lysis in the presence of specific solubilizing agents to optimize yield. Button dialysis (4) or microdrops (5) can screen a wide range of $\mathrm{pH}$ and additives, and these methods have been successful in improving solubility and crystal formation (6). The latter techniques, however, are often limited by methodologies requiring low protein concentrations that cannot be increased significantly throughout the course of study. Here we report a novel strategy to rapidly survey a diverse number of solubilization reagents while simultaneously removing the MBP tag. This "fusion protein cleavage screen" combines the enhanced expression and solubility properties of MBP with the efficiency of sparse matrix screening. As a case study, we report results for the 42-kDa catalytic domain of human type II inosine monophosphate dehydrogenase (IMPDH2 $\Delta$ ), which is being studied by X-ray crystallography in our laboratory.

Initial attempts to purify the catalytic domain IMPDH2S met with low expression and poor solubility. Use of the H-MBP-3C vector (7) dramatically increased expression. Cells were grown
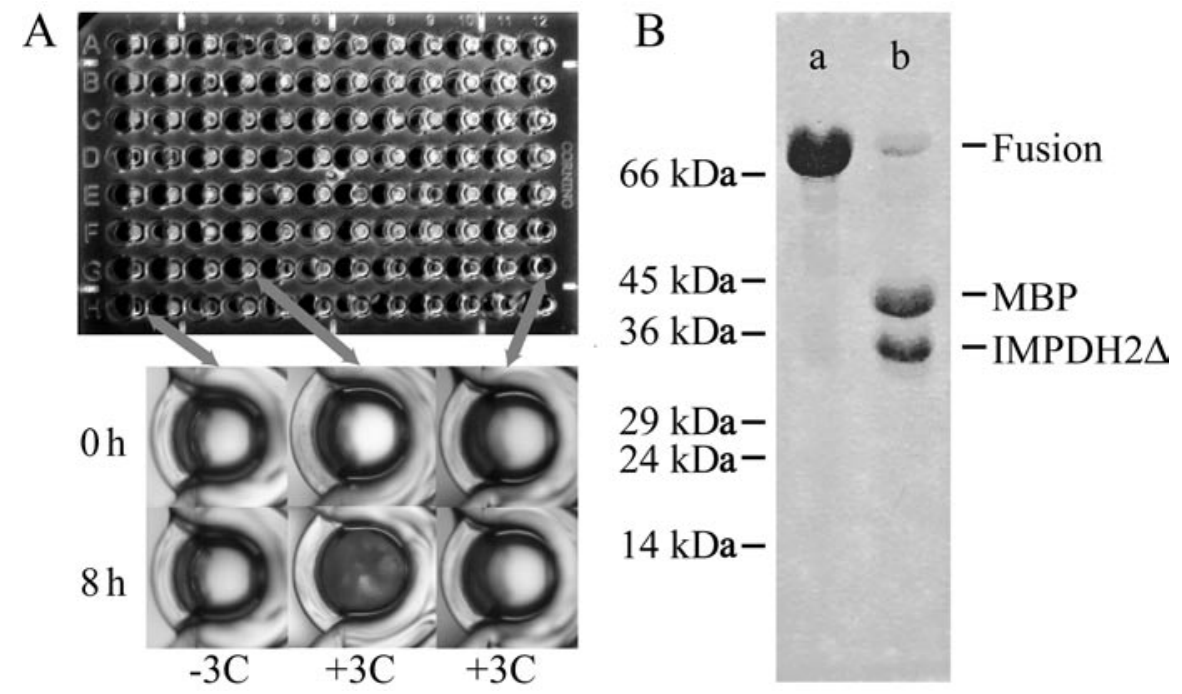
$\mathrm{M}$ imidazole (Sigma), and trials were conducted to cleave the eluted fusion protein, although these were unsuccessful.

was developed for determination of solubilization conditions. We again employed the viral $3 \mathrm{C}$ protease of type $\mathrm{H}-3$ Cpro because it is highly specific, number of ionic conditions $(7,8)$. Similarly, MBP is soluble at $>25 \mathrm{mg} /$ $\mathrm{mL}$ in $10 \mathrm{mM}$ Tris, $\mathrm{pH} 7.5$ (9) and is very soluble from $\mathrm{pH} 5.0$ to 9.0. Before

Figure 1. Fusion protein cleavage screen and fusion protein cleavage of $\mathrm{H}-\mathrm{MBP}-3 \mathrm{C}-\mathrm{IMPDH} 2 \Delta$. (A) Fusion protein cleavage screen. A 96-well plate with sitting drop platforms containing the cleavage reactions after overnight incubation at $20^{\circ} \mathrm{C}$ with a well solution of water. (Inset) Expanded views of initial $(0 \mathrm{~h})$ and $8 \mathrm{~h}$ time points are shown in rows. Comparing the two time points for the protein-only control (left) demonstrated no independent precipitation of the fusion protein. Two representative conditions are illustrated by comparison of the two time points. Both unsuccessful (middle, precipitated) and successful (right, unprecipitated) examples are depicted. An additional plate of drops with protein and additive was run to confirm the solubility in the absence of $3 \mathrm{C}$ protease (data not shown). (B) Fusion protein cleavage of H-MBP-3C-IMPDH2 $\Delta$. The Coomassie ${ }^{\circledR}$ Blue-stained sodium dodecyl sulfate polyacrylamide gel electrophoresis (SDS-PAGE) gel demonstrated the fusion protein before cleavage (lane a) and after overnight cleavage with $3 \mathrm{C}$ protease (lane b). MBP, maltose binding protein; IMPDH $2 \Delta$, the $42-\mathrm{kDa}$ catalytic domain of human type II inosine monophosphate dehydrogenase.

in $\mathrm{LB}$ broth at $37^{\circ} \mathrm{C}$ to an absorbance (A) at $600 \mathrm{~nm}$ of 0.6 and induced with (IPTG; Sigma, St. Louis, MO, USA) for $4 \mathrm{~h}$. The cells were harvested by centrifugation and suspended in buffer A [10 mM NaH $\mathrm{PO}_{4} / \mathrm{Na}_{2} \mathrm{HPO}_{4}$ buffer, pH 7.5, with $0.25 \mathrm{M} \mathrm{NaCl}$, and 0.1 $\mathrm{mM}$ dithiothreitol (DTT)] and then lysed at $4^{\circ} \mathrm{C}$ by sonication, clarified,
and the supernatant passed over $\mathrm{Ni}$ $\mathrm{NTA}^{\circledR}$ resin (Qiagen, Valencia, CA, USA). However, the protein precipitated during $3 \mathrm{C}$ protease cleavage on the resin. Therefore, the protein was 
cleavage of H-MBP-3C-IMPDH2 $\Delta$, the fusion protein was soluble at more than $10 \mathrm{mg} / \mathrm{mL}$ in $10 \mathrm{mM}$ Tris, $\mathrm{pH}$ 7.5. Therefore, samples were prepared with $10 \mathrm{mM}$ Tris buffer, $\mathrm{pH} 7.5,1 \mathrm{mM}$ DTT, at $2.5,5.0$, and $10 \mathrm{mg} / \mathrm{mL}$ protein concentrations.

For sparse matrix screens, the Crystal Screen ${ }^{\mathrm{TM}}$, Crystal Screen 2, Additive Screen, and Detergent Screen (all from Hampton Research, Aliso Viejo, CA, USA) were utilized, as well as additional solutions of amino acids (10), sugars (11), substrates of IMPDH or analogs thereof, and stocks of glycerol or urea at high concentration. These reagents were each screened separately at a variety of different concentrations over a wide $\mathrm{pH}$ range. Aside from crystal screening reagents, conditions designed to enhance solubility, such as the JBS Solubility Kit (Jena Bioscience GmbH, Jena, Germany) (12) or other commercial additive and detergent screens may be suitable, although these were not tested

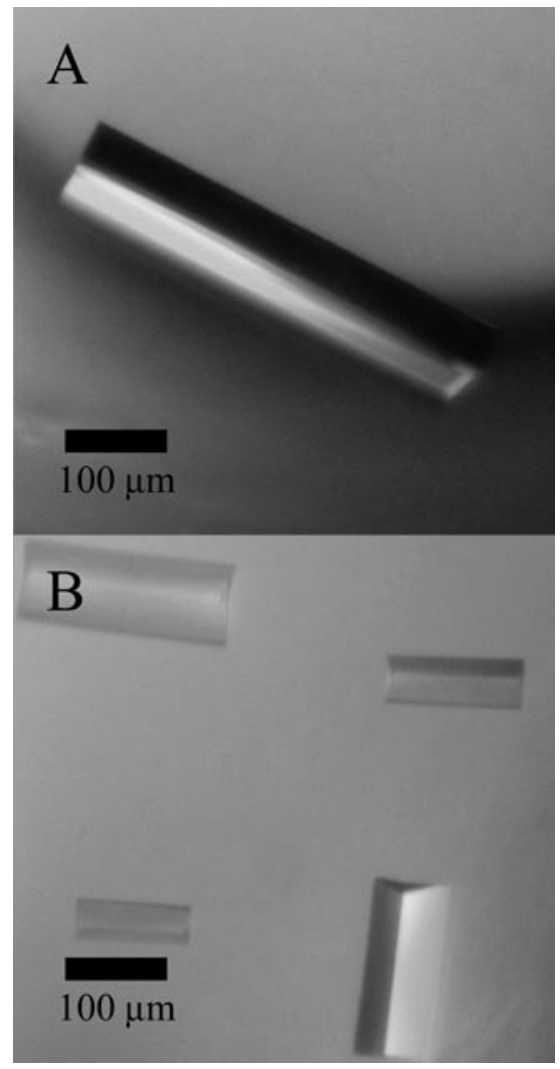

Figure 2. Crystals obtained from optimized conditions. (A) Crystal optimized from $2 \mathrm{M}$ urea. (B) Crystal optimized from $20 \%$ glycerol. here. Matrix screening solutions were dispensed onto the drop platform of a 96-well sitting drop plate (Corning, Corning NY, USA) or an IMPACT ${ }^{\circledR}$ plate (Hampton Research) (Figure 1A). The $2-\mu \mathrm{L}$ drops of protein solution were mixed with 1 or $2 \mu \mathrm{L}$ additive and $1 \mu \mathrm{L}$ protease, resulting in a 1:50 (w/w) ratio of protease to target protein. For the IMPACT plates, the drop was covered with paraffin oil to prevent dehydration. Plates were sealed and incubated for $8 \mathrm{~h}$ at $4^{\circ}$ or $20^{\circ} \mathrm{C}$. Clear drops were run on a PhastGel ${ }^{\mathrm{TM}}$ (Amersham Biosciences, Piscataway, NJ, USA) $12.5 \%$ sodium dodecyl sulfate polyacrylamide gel electrophoresis (SDS-PAGE) gel to determine whether cleavage had occurred (Figure 1B).

For H-MBP-3C-IMPDH2 $\Delta$, several drops remained clear after incubation. Cleavage was nearly complete for most trials except those containing $\mathrm{pH}$ $>9.0$ or $<4.0, \mathrm{ZnCl}_{2}$, or imidazole, which appeared to inhibit cleavage, respectively. Conditions that successfully solubilized IMPDH2 $2 \Delta$ included increasing the $\mathrm{pH}$ to 8.5 , chaotropic salts (2 M urea), osmolytes (20\% w/v glycerol, $3 \% \mathrm{w} / \mathrm{v}$ polyethylene glycol 400 , or $5 \%$ w/v Jeffamine M600), and substrate $(20 \mathrm{mM}$ inosine monophosphate). These conditions were optimized further, yielding solubility levels of $8 \mathrm{mg} / \mathrm{mL}$. The established conditions were used to maintain solubility during bulk cleavage and after removal of MBP and 3C protease by anion exchange. The solubilization reagents were retained in crystallization trials that produced diffraction quality crystals (Figure 2).

By combining the increased expression and ease of purification of a 6His-MBP fusion protein with the microdrop method of sparse matrix screening, we have developed an efficient method for rapid determination of conditions that maximize solubility. Though commercial screens were optimized for crystallization, they proved useful in surveying solubility. For minimal concentration changes, IMPACT plates can be utilized with the drop containing fusion protein, additive, and protease covered by paraffin oil. The upper limits of solubility can be tested by vapor diffusion for reaction mixtures in sitting drops placed over wells containing only the additive solutions. If initial conditions are too concentrated and/or precipitation is reversible, more dilute conditions can be found by placing reaction drops over wells containing additional water. Notably, supersaturation can be achieved in these vapor diffusion experiments, resulting in crystals. However, these were not suitable for $\mathrm{X}$-ray diffraction due to their fragility and lack of a defined habit.

Despite the wide range of $\mathrm{pH}$, salts, osmolytes, detergents, and amino acids, $3 \mathrm{C}$ protease robustly cleaved the fusion protein, and several solubilizing conditions were identified. Like standard microdrop methods, a lower quantity of sample was required per condition than with dialysis. This permitted a large sampling of additives and rapid detection of solubility enhancement. The H-MBP-3C vector utilized in the work and the GST fusion vector pGEX-6P (Amersham Biosciences) should be amenable to this technique, although MBP generally provides greater solubility. This method may not be suited to thrombin or Factor Xa, due to their less robust activities (see www4.amershambiosciences.com/ APTRIX/upp01077.nsf/Content/lsn online_article_190402_c). Notably, the method should be amenable to nanoliter-scale drop sizes (13) with the caveat that sufficient protein is needed to confirm protease cleavage. Perhaps this could be accomplished with a more sensitive stain for SDS-PAGE. Overall, the microdrop fusion protein cleavage screen may be of general utility for proteins with poor solubility that can only be expressed as fusion constructs.

\section{ACKNOWLEDGMENTS}

The authors thank Dr. L. Hedstrom for the type II IMPDH construct, Drs. $S$. Pascal and A. Alexandrov for the $H$ $M B P-3 C$ and $H$-3Cpro vectors, and $D r$. R. Basavappa, E. Petri, and B. Tolbert for helpful discussions. This research was funded by National Institutes of Health (NIH) grant nos. GM63162 (J.E.W.) and GM525991 (B.M.G.). 


\section{COMPETING INTERESTS STATEMENT}

The authors declare no competing interests.

\section{REFERENCES}

1.Kapust, R.B. and D.S. Waugh. 1999. Escherichia coli maltose-binding protein is uncommonly effective at promoting the solubility of polypeptides to which it is fused. Protein Sci. 8:1668-1674.

2.Smyth, D.R., M.K. Mrozkiewicz, W.J. McGrath, P. Listwan, and B. Kobe. 2003. Crystal structures of fusion proteins with large-affinity tags. Protein Sci. 12:1313-1322.

3.Bagby, S., K.I. Tong, and M. Ikura. 2001. Optimization of protein solubility and stability for protein nuclear magnetic resonance. Methods Enzymol. 339:20-41.

4.Bagby, S., K.I. Tong, D. Liu, J.R. Alattia, and M. Ikura. 1997. The button test: a small scale method using microdialysis cells for assessing protein solubility at concentrations suitable for NMR. J. Biomol. NMR 10:279282.

5.Lepre, C.A. and J.M. Moore. 1998 Microdrop screening: a rapid method to optimize solvent conditions for NMR spectroscopy of proteins. J. Biomol. NMR 12:493-499.

6.Collins, B.K., S.J. Tomanicek, N. Lyamicheva, M.W. Kaiser, and T.C. Mueser. 2004. A preliminary solubility screen used to improve crystallization trials: crystallization and preliminary X-ray structure determination of Aeropyrum pernix flap endonuclease-1. Acta Crystallogr. D Biol. Crystallogr. 60:1674-1678.

7.Alexandrov, A., K. Dutta, and S.M. Pascal. 2001. MBP fusion protein with a viral protease cleavage site: one-step cleavage/purification of insoluble proteins. BioTechniques 30:1194-1198.

8.Cordingley, M.G., P.L. Callahan, V.V. Sardana, V.M. Garsky, and R.J. Colonno. 1990. Substrate requirements of human rhinovirus $3 \mathrm{C}$ protease for peptide cleavage in vitro. J. Biol. Chem. 265:9062-9065.
9.Quiocho, F.A., J.C. Spurlino, and L.E. Rodseth. 1997. Extensive features of tight oligosaccharide binding revealed in highresolution structures of the maltodextrin transport/chemosensory receptor. Structure 5:997-1015.

10.Golovanov, A.P., G.M. Hautbergue, S.A. Wilson, and L.Y. Lian. 2004. A simple method for improving protein solubility and long-term stability. J. Am. Chem. Soc. 126:8933-8939.

11.Davis-Searles, P.R., A.J. Saunders, D.A. Erie, D.J. Winzor, and G.J. Pielak. 2001. Interpreting the effects of small uncharged solutes on protein-folding equilibria. Annu. Rev. Biophys. Biomol. Struct. 30:271-306.

12.Jancarik, J., R. Pufan, C. Hong, S.H. Kim, and R. Kim. 2004. Optimum solubility (OS) screening: an efficient method to optimize buffer conditions for homogeneity and crystallization of proteins. Acta Crystallogr. D Biol. Crystallogr. 60:1670-1673.

13.Luft, J.R., R.J. Collins, N.A. Fehrman, A.M. Lauricella, C.K. Veatch, and G.T. DeTitta. 2003. A deliberate approach to screening for initial crystallization conditions of biological macromolecules. J. Struct. Biol. 142:170-179.

Received 13 July 2005; accepted 14 August 2005.

Address correspondence to Joseph E. Wedekind, Department of Biochemistry and Biophysics, University of Rochester School of Medicine and Dentistry, 601 Elmwood Avenue, Box 712, Rochester, NY 14642, USA. e-mail: Joseph_Wedekind@urmc. rochester.edu

To purchase reprints of this article, contact

Reprints@BioTechniques.com 